\title{
Staphylococcus aureus: visitando uma cepa de importância hospitalar
}

\section{Staphylococcus aureus: visiting a strain of clinical importance}

André Luis dos Santos ${ }^{1}$, Dilvani Oliveira Santos², Cícero Carlos de Freitas², Bruno Leal Alves Ferreira ${ }^{3}$, llídio F. Afonso ${ }^{4}$, Carlos Rangel Rodrigues ${ }^{4}$, Helena C. Castro ${ }^{2}$

\begin{tabular}{|c|c|}
\hline & \\
\hline taphylococcus aureus & ccus aureus é uma bactéria do grupo dos cocos gram-positivos que faz parte da microbiota \\
\hline nicrobian & $\begin{array}{l}\text { humana, mas que pode provocar doenças que vão desde uma infecção simples, } \\
\text { furúnculos, até as mais qraves, como pneumonia meninqite, endocardite, síndrome }\end{array}$ \\
\hline MRSA & e septicemia, entr \\
\hline VISA & dos antibióticos, mas, devido a sua en \\
\hline heteroVISA & $\begin{array}{l}\text { espécies de maior importância no quadro das infecções hospitalares e comunitárias. Neste artigo faremos } \\
\text { uma revisão sobre esse agente infeccioso e as bases dos mecanismos das patologias por ele provocadas, } \\
\text { de forma a ressaltar a necessidade de mantê-lo como alvo para o desenho de novos antibióticos. }\end{array}$ \\
\hline
\end{tabular}

\section{abstract}

Staphylococcus aureus is a bacterium from Gram-positive coccus group, which is part of the human microbiota. It may cause diseases that may vary from simple infections (i.e., pimples and furuncles) to severe infections, such as pneumonia, meningitis, endocarditis, toxic shock syndrome and septicemia, among others. This bacterium was one of the first bacteria affected by antibacterial agents, however, its ability of adaptation and resistance turns it into an important hospital and communitarian pathogenic species of great concern. In this article we will discuss some important points related to the S. aureus and the pathologies related to it to reinforce it as a target for the design of new antibiotics.

\section{key words}

S. aureus

Microbial resistance

MRSA

VISA

heteroVISA

VRSA

\section{Introdução}

O Staphylococcus aureus é uma bactéria esférica, do grupo dos cocos gram-positivos, freqüentemente encontrada na pele e nas fossas nasais de pessoas saudáveis. Entretanto pode provocar doenças, que vão desde uma simples infecção (espinhas, furúnculos e celulites) até infecções graves (pneumonia, meningite, endocardite, síndrome do choque tóxico, septicemia e outras). A implantação da antimicrobianoterapia, no início da década de 1930, com o emprego da sulfanilamida (descoberta por Gerard Domagk em 1932), 
aparentemente ditava o fim das doenças infecciosas. No entanto, no final daquela década surgiram as primeiras cepas de $S$. aureus resistentes àquele quimioterápico. Desde então, o S. aureus tem ganhado esta "batalha", posto que novas cepas resistentes têm surgido a cada novo antibiótico introduzido no tratamento das patologias a ele atribuídas. Nesta revisão abordaremos os conceitos sobre o $S$. aureus, enfocando principalmente aspectos estruturais e morfológicos, características bioquímicas e tratamento atual, com o objetivo de aumentar a compreensão sobre essa bactéria e as patologias por ela provocadas.

\section{Identificação e caracterização}

Os Staphylococcus são cocos Gram e catalase-positivos, com aproximadamente 0,5 a 1,5 $\mu \mathrm{m}$ de diâmetro, imóveis, não-esporulados e geralmente não-encapsulados. Essa bactéria pode apresentar-se em diversas formas, que vão desde isolados, aos pares, em cadeias curtas, ou agrupados irregularmente (com aspecto semelhante a um cacho de uvas), devido à sua divisão celular, que ocorre em três planos perpendiculares (Figura 1) $)^{(9,18,40)}$. O Staphylococcus foi descrito pela primeira vez em 1880 , em pus de abscessos cirúrgicos, pelo cirurgião escocês Alexandre Ogston e atualmente é um dos microorganismos mais comuns nas infecções piogênicas em todo o mundo.

O gênero Staphylococcus pertence à família Micrococcae, juntamente como os gêneros Planococcus, Micrococcus e Stomatococcus. Atualmente, o gênero Staphylococcus possui 33 espécies, sendo que 17 delas podem ser isoladas de amostras biológicas humanas. Geralmente, esse gênero faz parte da microbiota da pele humana normal e de outros sítios anatômicos. A espécie de maior interesse médico, principalmente em ambiente nosocomial, é o S. aureus, que está freqüentemente relacionado com diversas infecções em seres humanos ${ }^{(9,18)}$.

As cepas de $S$. aureus crescem em meios comuns, caldo ou ágar simples, $\mathrm{pH}=7$, à temperatura ótima de $37^{\circ} \mathrm{C}$. As colônias formadas em placa, após 18-24 horas de incubação, apresentam-se arredondadas, lisas e brilhantes (Figura 1). A coloração dessas colônias varia desde o acinzentado até o amarelo-ouro, em que a pigmentação aumenta com o tempo de incubação prolongado, não chegando a ser formada nos casos de crescimento em condições anaeróbicas, ou na cultura em caldo. Em placas de ágar sangue, um halo de hemólise desenvolve-se em torno das colônias formadas

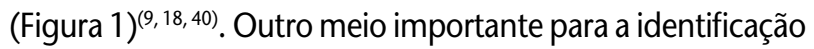
do S. aureus é o ágar manitol-sal, seletivo para essa espécie, uma vez que o S. aureus consegue fermentar o manitol, produzindo ácido lático. Essa espécie se desenvolve também na presença de 7,5\% de $\mathrm{NaCl}$, que estimula a produção de coagulase, enzima que caracteriza a espécie ${ }^{(9,18)}$.

\section{Fontes de infecção}

A distribuição de S. aureus é muito ampla, visto que essa bactéria é significativamente capaz de resistir à dessecação e ao frio, podendo permanecer viável por longos períodos em partículas de poeira. Esse microorganismo pode ser encontrado no ambiente de circulação do ser humano, sendo o próprio homem seu principal reservatório, além de estar presente em diversas partes do corpo, como fossas nasais, garganta, intestinos e pele. Desses sítios anatômicos, as narinas possuem o maior índice de colonização, cuja prevalência é de cerca de $40 \%$ na população adulta, podendo ser ainda maior dentro de hospitais ${ }^{(7,8,11)}$.

O S. aureus encontrado nas fossas nasais ou na pele de neonatos, crianças e adultos pode, a partir desses sítios, alcançar outras regiões da pele e das mucosas. Caso as barreiras naturais, isto é, pele e mucosas, estejam comprometidas por trauma ou cirurgia, o $S$ aureus pode se alojar no tecido e provocar uma lesão local(31,43).

A colonização nasal pelo $S$. aureus é desprovida de sintomas, ou seja, o individuo não desenvolve infecção. Essa colonização assintomática tem grande importância clínica, uma vez que, com as narinas colonizadas, o indivíduo contamina as próprias mãos e passa a ser veículo de transferência da bactéria no mecanismo de infecções por contato. Assim, principalmente em hospitais, o hospedeiro assintomático pode ser um paciente, um visitante, ou mesmo um profissional de saúde. De acordo com alguns estudos, o carreamento nasal também contribui para a transmissão da bactéria por disseminação aérea ${ }^{(8,11,33)}$.

Em hospitais, principalmente em berçários e unidades de terapia intensiva (UTIs), é rotina o isolamento de pacientes colonizados. O S. aureus também traz riscos para pacientes que fazem diálise, queimados, diabéticos e HIV-positivos, visto que pode causar diversos processos infecciosos, que variam desde infecções cutâneas crônicas (relativamente benignas) até infecções sistêmicas (potencialmente fatais). As infecções cutâneas incluem foliculite simples e impetigo, assim como furúnculos e carbúnculos, que afetam o tecido subcutâneo e produzem efeitos sistêmicos, como febre ${ }^{(6,8,11)}$.

Infecções da pele e tecidos moles são comuns, tanto em pacientes da comunidade quanto em hospitalizados 


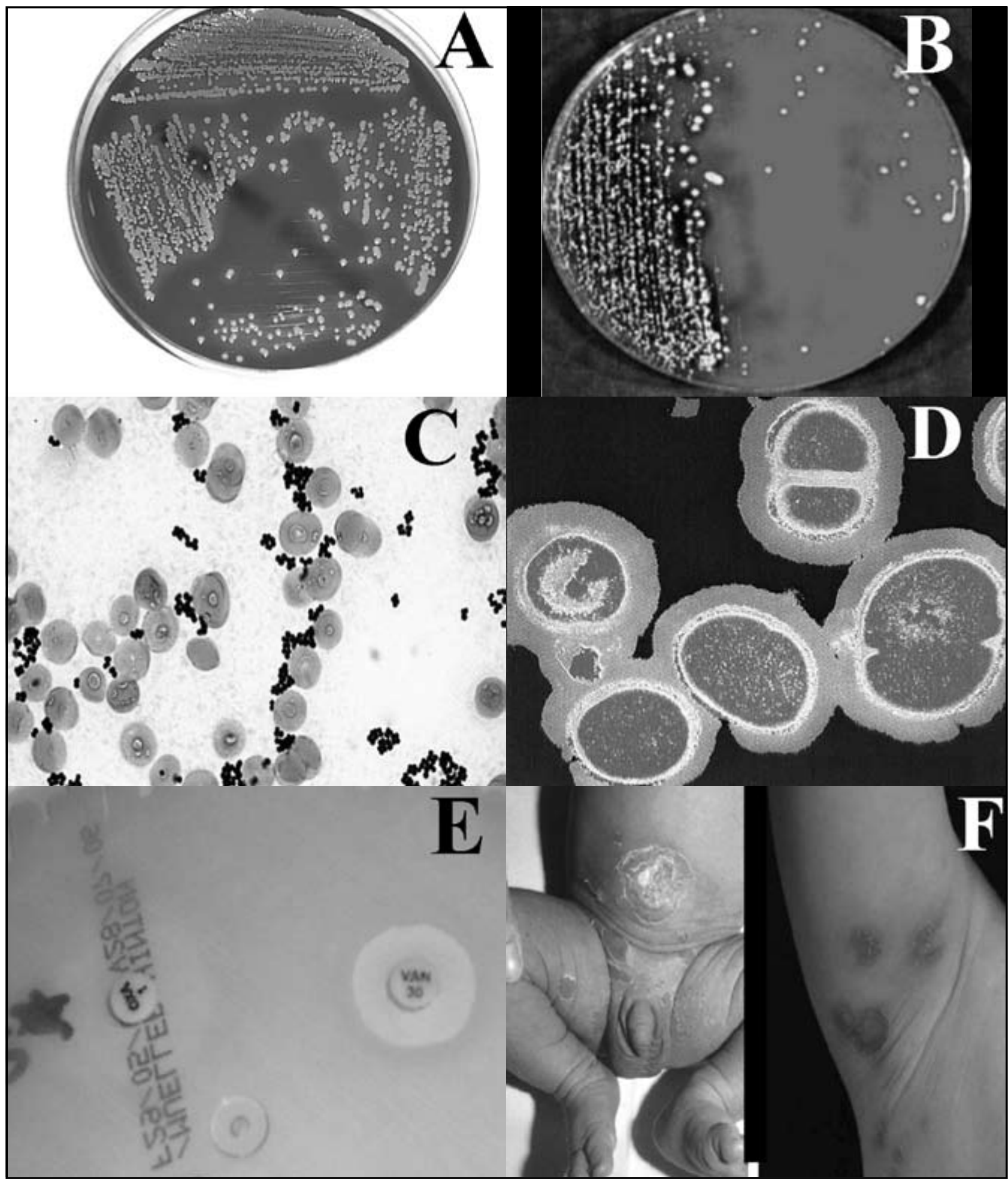

Figura 1 - Características do S. aureus. A: colônias crescidas em meio de àgar-sangue; B: visão macroscópica de colônias de VRSA; C: S. aureus corado pelo método de Gram; D: colônias de VRSA em microscopia eletrônica (direita); E: antibiograma de uma cepa MRSA; notar o halo de inibição em torno do disco de vancomicina, o que não ocorre no disco de oxacilina, caracterizando a resistência a este antibiótico; F: manifestações cutâneas da síndrome da pele escaldada (esquerda) e impetigo (direita)

VRSA: Staphylococcus aureus resistente à vancomicina; MRSA: Staphylococcus aureus resistente à meticilina.

(Figura 1). Essas infecções podem atingir desde regiões superficiais até os tecidos mais profundos, sendo o $\mathrm{S}$. aureus o agente mais comum. Em indivíduos saudáveis, a pele normal é colonizada por aproximadamente oito a 10 espécies de Staphylococcus, incluindo o S. aureus. Infecções em usuários de drogas intravenosas também têm sido associadas ao $S$. aureus $^{(31)}$. As toxinas estafilocócicas são responsáveis pela necrose epidérmica tóxica (síndrome 
da pele escaldada) e pela síndrome do choque tóxico. Os Staphylococcus também são capazes de produzir infecções alimentares devido à produção de exotoxinas durante 0 crescimento em alimentos contaminados $(8,11,23)$.

O S. aureus é freqüentemente isolado de feridas cirúrgicas infectadas, que podem representar focos para desenvolvimento de infecções sistêmicas. A broncopneumonia estafilocócica é observada usualmente em idosos, e está associada à pneumonia viral como fator predisponente. A pneumonia nosocomial produzida por $S$. aureus ocorre em casos de doença pulmonar obstrutiva crônica (DPOC), intubação e aspiração, e as doenças malignas subjacentes são reconhecidas como fatores de risco para o desenvolvimento de uma bacteremia por S. aureus ${ }^{(7,8,}$ 11). Por ser um dos componentes normais da microbiota da pele, pacientes que fazem uso de cateteres endovenosos podem ser infectados pelo $S$. aureus por meio de sua invasão a partir do local de inserção do cateter. A bactéria é capaz de migrar pelo cateter até chegar à circulação sangüínea, podendo levar a quadros graves de bacteremia, principalmente se a microbiota abrigar cepas resistentes à meticilina, denominadas MRSA (S. aureus resistente à meticilina) $)^{(16)}$.

A bacteremia pode causar infecções em sítios anatômicos distantes, como endocardites, osteomielites, pioartrites e formação de abscessos metastáticos, em particular em pele, tecidos subcutâneos, pulmões, fígado, rins e cérebro. O S. aureus é a segunda maior causa de meningites associadas a derivações ventriculoperitoneais, sendo um dos muitos agentes responsáveis por peritonite em pacientes submetidos à diálise peritoneal contínua ${ }^{(8,11,15)}$. A meningite estafilocócica se manifesta também em pacientes com alteração do sistema nervoso central (SNC), traumatismos, cirurgia, tumores malignos e hidrocefalia.

O S. aureus é a bactéria mais comum também em infecções ósseas, artrites sépticas e infecções de próteses ósseas. Essas infecções se caracterizam pela dificuldade de tratamento, que pode incluir intervenções cirúrgicas e longos períodos de antibioticoterapia. A relação do $S$. aureus com infecções ósseas está no fato de essa bactéria ser capaz de expressar numerosas proteínas de superfície, denominadas adesinas, que permitem a adesão aos componentes da matriz óssea (fibronectina), laminina, colágeno, entre outros. Algumas cepas de $S$. aureus podem sobreviver intracelularmente em osteoblastos, às vezes metabolicamente inativas, tornandose tolerantes à ação dos antibióticos. Além disso, o S. aureus pode formar biofilmes na superfície de materiais estranhos ao organismo, como cateteres endovenosos e próteses, que funcionam como locais protegidos contra a ação de antibióticos e do sistema imunológico do hospedeiro(13).

\section{Mecanismos de patogenicidade}

As doenças provocadas pelo $S$. aureus podem ser decorrentes da invasão direta dos tecidos, de bacteremia primária ou, exclusivamente, ser devidas às toxinas que ele produz ${ }^{(1,3,34)}$. Essas infecções podem se localizar em um ou em múltiplos sítios, e, de acordo com a localização e outras características, recebem diferentes designações, como foliculite (infecção do folículo piloso); sico (bichodo-pé); carbúnculo; antraz; furúnculos localizados na região cervical posterior; hordéolo (terçol); hidradenite (inflamação das glândulas sudoríparas); e impetigo ${ }^{(1,3,34)}$. Além das piogênicas, o $S$. aureus pode causar outras infecções mesmo durante um processo infeccioso ou não ${ }^{(1,3,34)}$. Esses diferentes mecanismos e patologias fazem com que o S. aureus possua várias características que, por vezes, não são encontradas em todas as cepas desse Gram-positivo, surgindo, entretanto, à medida que nele são identificadas novas e diferentes propriedades patogênicas ${ }^{(9,20)}$.

Classicamente, a análise do mecanismo de invasão do S. aureus revela que, no primeiro momento, essa bactéria adere à pele ou à mucosa para, em seguida, romper as barreiras do epitélio, comprometendo estruturas de ligações intercelulares, como desmossomos e junções de aderência ${ }^{(17)}$. Após a invasão do epitélio, o $S$. aureus utiliza diversas estratégias para permitir a sua sobrevivência e proliferação no organismo hospedeiro. Essas estratégias estão relacionadas com a opsonização do complemento, a neutralização da fagocitose e a inibição das respostas imunes humoral e celular.

A capacidade de colonização e a patogenicidade do $S$. aureus são, portanto, uma conseqüência de seus fatores de virulência, os quais têm papel relevante na adesão celular, na captação de nutrientes e na sua evasão da resposta imunológica do hospedeiro. Esses fatores de virulência podem ser classificados, basicamente, nas três seguintes categorias: a) fatores relacionados com a aderência às células do hospedeiro ou à matriz extracelular, como a produção de moléculas de fibrinogênio, fibronectina, colágeno ou da enzima coagulase; b) fatores relacionados com a evasão da defesa do hospedeiro, como diversas enterotoxinas estafilocócicas (SEs A-E, G-J, K, L, M, O e P), a toxina da síndrome do choque tóxico (TSST), a proteína $A$, lipases e polissacarídeos capsulares; e c) fatores relacionados com a invasão na célula do hospedeiro e a penetração nos tecidos 
ou adesão de superfícies de cateteres e próteses, os quais incluem as proteínas (toxinas) $\alpha, \beta, \delta, \gamma$ e $\delta$ - hemolisinas (Tabelas 1 e 2)(43). O S. aureus contém ainda, na estrutura de sua parede celular, polissacarídeos e proteínas antigênicas, bem como outras moléculas importantes, as quais podem induzir uma resposta imunológica no hospedeiro. Entre essas outras moléculas podemos citar o ácido tecóico, o glicanopeptídio, a proteína $A$, além da presença de cápsula e de adesinas (Tabela 1)(20,29).

O alto potencial infeccioso do S. aureus não está restrito apenas à sua facilidade de multiplicação e disseminação nos tecidos, mas também à produção de moléculas com grande poder patogênico, que incluem enzimas e toxinas (Tabela 2). As betalactamases, coagulases, hialuronidases e catalases são algumas das enzimas produzidas para esse fim (Tabela 2). Além dessas enzimas, o S. aureus também produz
DNAses, lipases, proteases e esterases ${ }^{(3,28,34)}$. Entre as toxinas produzidas por esse patógeno destacam-se as seguintes: alfa, beta e gama toxinas, a leucocidina, a esfoliatina, a toxina do choque tóxico e as enterotoxinas (Tabela 2) ${ }^{(3,28,34)}$.

Os diferentes tipos de toxina produzidos pelo S. aureus podem induzir uma resposta imune, diferenciada para cada hospedeiro, que é responsável pelas manifestações clínicas características do processo infeccioso e que determina o grau de severidade dos sintomas sistêmicos. Podemos citar, a título de exemplo, a TSST-1 e a toxina esfoliativa estafilocócica, que podem causar as síndromes do choque tóxico e da pele escaldada (ou doença de Ritter), respectivamente, em certos pacientes, além da leucocidina de Panton-Valentine (PVL), que está associada a infecções severas de pele, furunculoses e pneumonia necrosante em crianças e jovens previamente saudáveis ${ }^{(17)}$.

\begin{tabular}{|c|c|}
\hline & $\begin{array}{l}\text { stituintes da par } \\
\text { no hospedeiro }\end{array}$ \\
\hline Constituinte & Definição e funções \\
\hline Ácido tecóico & $\begin{array}{l}\text { Polissacarídeo espécie-específico constituído de fosfato de ribitol e } \mathrm{N} \text {-acetilglucosamina, capaz de } \\
\text { ativar a via alternativa do complemento e estimular a produção de citosinas }\end{array}$ \\
\hline Glicanopeptídio & $\begin{array}{l}\text { Polímero de polissacarídeo que atua como agente quimiotático para leucócitos polimorfonucleares } \\
\text { e induz a produção de IL-1, que vai atuar como elo entre as respostas inflamatória e imune, e } \\
\text { opsoninas, que revestem a bactéria, tornando-a mais facilmente fagocitada }\end{array}$ \\
\hline Proteína A & $\begin{array}{l}\text { Proteína ligada ao peptideoglicano presente em mais de } 90 \% \text { das cepas de } S \text {. aureus e que se liga à } \\
\text { porção Fc da molécula de lgG, contribuindo para a geração de efeitos anticomplementares, quimiotáticos, } \\
\text { antifagocitários, com liberação de histamina, reações de hipersensibilidade e lesão plaquetária }\end{array}$ \\
\hline Cápsula & $\begin{array}{l}\text { Estrutura polissacarídica que envolve a parede celular da maioria das cepas de } S \text {. aureus, protegendo a } \\
\text { bactéria da fagocitose mediada pelo complemento (C3b) por parte dos neutrófilos polimorfonucleares, } \\
\text { aumentando a virulência e a capacidade de invasão dos tecidos e da corrente sangüínea, a partir } \\
\text { de um foco periférico, e ativando o complemento por via alternativa }\end{array}$ \\
\hline Adesinas & $\begin{array}{l}\text { Moléculas que fazem parte da estrutura gelatinosa do glicocálix (que envolve a célula bacteriana) e } \\
\text { que se ligam aos receptores químicos encontrados na superfície das células epiteliais do hospedeiro, } \\
\text { promovendo a aderência da bactéria a essas células }\end{array}$ \\
\hline
\end{tabular}

IL-1: interleucina 1; IgG: imunoglobulina $\mathrm{G}$.

Enzimas e toxinas produzidas pelo $S$. aureus que participam dos mecanismos de patogenicidade Tabela 2 e de resistência a esse patógeno

\begin{tabular}{lll}
\hline Nome & Classe & Função \\
Betalactamases & Enzima & $\begin{array}{l}\text { Inativa os antibióticos betalactâmicos (exs.: penicilinas e cefalosporinas) pela } \\
\text { abertura do anel betalactâmico (exs.: penicilinases e cefalosporinases) }\end{array}$ \\
Enzimagulase & $\begin{array}{l}\text { Converte o fibrinogênio em fibrina, independentemente da presença do ín } \\
\text { Ca }{ }^{+2} \text { e dos fatores V, VI e VII da coagulação sangüínea, provocando a deposição } \\
\text { de fibrina em torno do microorganismo e dificultando a fagocitose celular }\end{array}$
\end{tabular}




\begin{tabular}{|c|c|c|}
\hline Hialuronidase & Enzima & $\begin{array}{l}\text { Despolimeriza o ácido hialurônico, agindo, assim, como fator de } \\
\text { propagação do microorganismo }\end{array}$ \\
\hline Catalase & Enzima & $\begin{array}{l}\text { Converte o peróxido de hidrogênio, que apresentaria uma ação tóxica } \\
\text { sobre a bactéria, em oxigênio e água }\end{array}$ \\
\hline Alfatoxina (alfa-hemolisina) & Toxina & $\begin{array}{l}\text { Pode apresentar quatro conformações diferentes, sendo capaz de lisar } \\
\text { hemácias e causar danos às plaquetas em casos de intoxicações graves }\end{array}$ \\
\hline Betatoxina (beta-hemolisina) & Toxina & $\begin{array}{l}\text { Degrada a esfingomielina, provocando lesões na membrana dos } \\
\text { eritrócitos e, conseqüentemente, conduzindo à hemólise }\end{array}$ \\
\hline Deltatoxina (delta-hemolisina) & Toxina & $\begin{array}{l}\text { Possui propriedades tensoativas, atuando como detergente e sendo } \\
\text { responsável pelos efeitos sobre as membranas de eritrócitos, macrófagos, } \\
\text { linfócitos, neutrófilos e plaquetas. É capaz, ainda, de inibir a absorção de } \\
\text { água pelo íleo, devido à alteração do mecanismo de ação do monofosfato } \\
\text { de adenosina cíclico (AMP-c), desencadeando uma diarréia aguda }\end{array}$ \\
\hline Gama-toxina (gama-hemolisina) & Toxina & $\begin{array}{l}\text { tolítica, cujo mecanismo ainda não foi } \\
\text { to }\end{array}$ \\
\hline PVL & Toxina & $\begin{array}{l}\text { Composta por dois componentes protéicos (S eF), que atuam sinergisticamente. } \\
\text { Essa proteína altera a permeabilidade da membrana e ataca os leucócitos } \\
\text { polimorfonucleares e os macrófagos. Essa alteração permite a entrada de } \\
\text { cátions, como o } \mathrm{Ca}^{+2} \text {, resultando na degranulação celular e induzindo a citólise }\end{array}$ \\
\hline Esfoliatina & Toxina & $\begin{array}{l}\text { Promove a clivagem do extrato granuloso da epiderme, causando síndromes } \\
\text { cutâneas severas (síndrome da pele escaldada e impetigo bolhoso) }\end{array}$ \\
\hline TSST-1 & Toxina & $\begin{array}{l}\text { Provoca febre, choque e envolvimento de sistemas orgânicos múltiplos, } \\
\text { incluindo erupção cutânea descamativa }\end{array}$ \\
\hline Enterotoxinas ( $A, B, C, D$ e $E)$ & Toxina & $\begin{array}{l}\text { Toxinas protéicas pirogênicas, termoestáveis, responsáveis pela intoxicação } \\
\text { alimentar, podendo provocar vômitos e diarréias }\end{array}$ \\
\hline
\end{tabular}

AMPc: monofosfato de adenosina cíclico; PVL: leucocidina Panton-Valentine; TSST-1: toxina da síndrome do choque tóxico.

\section{Antibioticoterapia versus resistência}

A implantação da antibioticoterapia no início da década de 1930, com o emprego da sulfanilamida (descoberta por Gerard Domagk, em 1932), aparentemente ditava o fim das doenças infecciosas. Contudo, ao analisarmos a evolução da resistência do $S$. aureus, observamos que, já no final daquela década, surgiam as primeiras cepas de $S$. aureus resistentes àquele quimioterápico (Figura 2). Com a entrada da penicilina em uso clínico, o $S$. aureus passou a desenvolver resistência a esse betalactâmico pela produção da betalactamase (penicilinase), capaz de hidrolisar o anel betalactâmico da penicilina, tornando-a inativa. Em 1944, apenas 5\% dos S. aureus eram resistentes à penicilina, enquanto em 1959 essa resistência já alcançava a taxa de $80 \%$, sendo estendida tanto à amoxicilina como à ampicilina ${ }^{(14,24,38)}$.

Em 1960 foi descoberta uma droga do grupo das penicilinas, denominada meticilina (a primeira penicilina semi-sintética posta em uso clínico), que não era suscetível à ação da betalactamase. Logo em seguida à meticilina vieram as cefalosporinas. Porém, no início da década de 1970, começaram a aparecer, com muita rapidez, cepas de $S$. aureus com resistência à meticilina identificadas pela sigla MRSA (S. aureus resistente à meticilina) (Figura 1), também resistentes aos demais betalactâmicos (cefalosporinas e outros). As cepas MRSA rapidamente se disseminaram em ambientes hospitalares, limitando, assim, a antibioticoterapia de combate às estafilococcias por $S$. aureus aos glicopeptídios vancomicina e teicoplanina.

A vancomicina é um glicopeptídio conhecido desde 1956, quando foi colocado à disposição da medicina graças aos trabalhos de Cormick et al. Entretanto foi deixada à parte justamente por causa do sucesso da meticilina, da oxacilina e de outras isoxazolilpenicilinas. A vancomicina é eficiente no tratamento das infecções causadas pelas cepas MRSA, apesar de apresentar efeitos nefrotóxicos e ototóxicos ${ }^{(25,35,43)}$. Novamente, o $S$. aureus ganhou a "batalha", pois em 1997 Hiramatsu, no Japão, descreveu uma cepa 


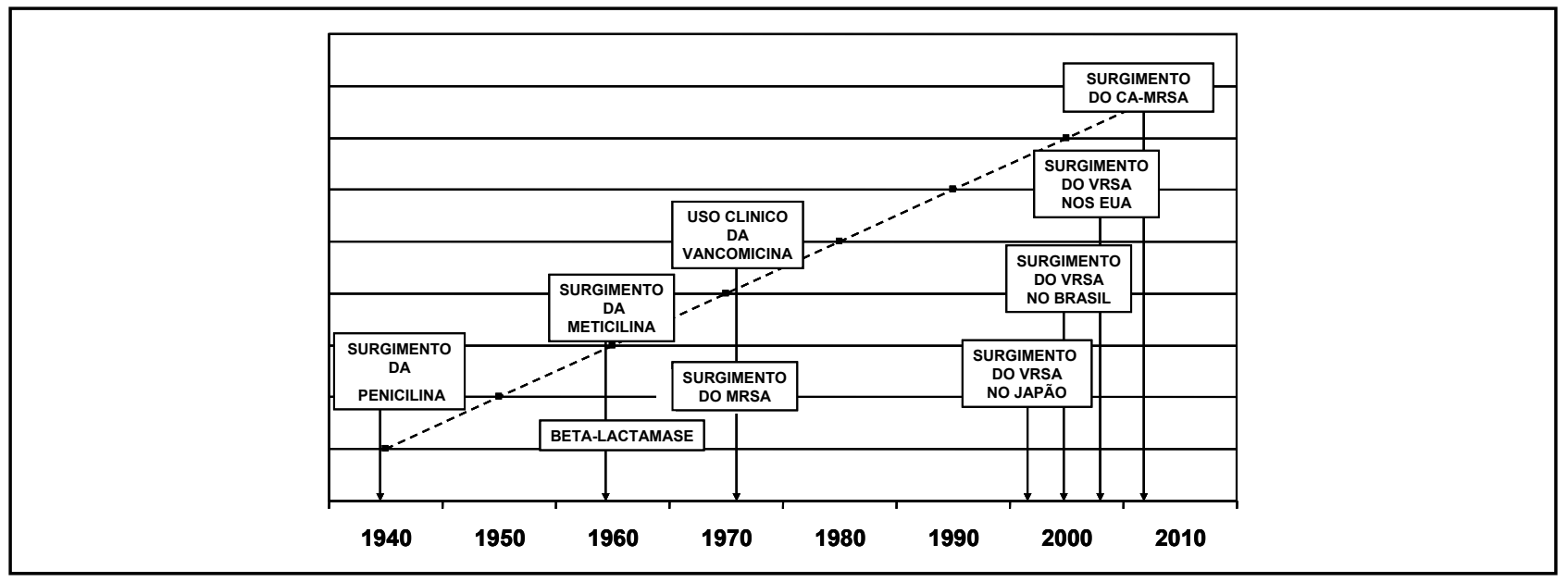

Figura 2 - Surgimento de alguns antibióticos e cepas resistentes do S. aureus nos séculos XX e XXI

desse Gram-positivo com resistência àquele glicopeptídio (S. aureus resistente à vancomicina [VRSA]).

A resistência do $S$. aureus aos antibióticos tem sido desenvolvida por mutações em seus genes ou pela aquisição de genes de resistência de outras bactérias da mesma espécie (ou até de outras). Geralmente, a resistência que ocorre por mutação gera uma alteração no sítio de ação do antibiótico, enquanto a resistência por aquisição de genes de resistência freqüentemente envolve a inativação ou a destruição da droga, sendo transmitida por plasmídeos e transposons ${ }^{(2,19,38)}$. Estudos genéticos demonstram que a atual prevalência de MRSA resultou principalmente da disseminação de alguns clones, com a descrição de apenas cinco clones no mundo. Atualmente, para a investigação de surtos, pode-se utilizar as caracterizações fenotípica e genotípica para avaliação da disseminação dessas cepas.

A literatura descreve que a resistência à meticilina é determinada por um gene cromossômico ( $m e c A$ ) da bactéria, o qual codifica para modificações no receptor do betalactâmico, estimulando a produção de uma proteína ligadora de penicilina (PPB2a) com baixa afinidade pelo antibiótico, resultando na resistência. Um estudo realizado em 1996, utilizando cepas analisadas em diferentes continentes, apontou as primeiras evidências da existência de cinco tipos de cassetes cromossomais estafilocócicos relacionados com a resistência à meticilina $\left(\mathrm{SCCmec} \mathrm{I,} \mathrm{II,} \mathrm{III,} \mathrm{IV} \mathrm{e} \mathrm{V)}{ }^{(43)}\right.$. Existem ainda cepas resistentes resultantes de mecanismos não relacionados ao $m e c A$, como a hiperproducão de betalactamase e MOD-AS.

O surgimento de cepas de Staphylococcus coagulasenegativa, resistentes à vancomicina, foi o primeiro indicativo de que essa bactéria estaria realizando mais um passo na escala da resistência aos antibióticos, provavelmente em decorrência de seu uso abusivo na antibioticoterapia. Outro indicativo foi o aparecimento, em hospitais dos EUA, de cepas de Enterococcus resistentes à vancomicina (VRE) isoladas de materiais clínicos ${ }^{(24,39,42)}$.

Em 1997 foi descrito, pelo Professor Keich Hiramatsu, da Universidade de Jutendo, Japão, um caso de uma cepa MRSA resistente à vancomicina isolada de uma ferida cirúrgica de um garoto de 4 meses ${ }^{(29,42,44)}$. Em 2000 foram encontradas, no Brasil, as primeiras cepas de $S$. aureus com resistência à vancomicina em um hospital de referência do município de Queimados, no Rio de Janeiro. Em 2002 foi encontrado, nos EUA, o primeiro isolado clínico de cepas VRSA, com concentração mínima inibitória $(\mathrm{CMl})=8 \mu \mathrm{g} / \mathrm{ml}$. Outras cepas resistentes foram relatadas em Japão, França, Reino Unido e Alemanha. A maioria desses isolados parece ter se desenvolvido a partir de infecções por MRSA pree$x^{x i s t e n t e s}{ }^{(4,41)}$. Esses dados, entre tantos outros, ratificam a necessidade urgente, já reconhecida pela Organização Mundial da Saúde (OMS), da descoberta e/ou síntese de novos antibióticos para o tratamento das cepas de $S$. aureus multirresistentes ${ }^{(24,38)}$. Outro fenômeno, comum à resistência à oxacilina e à vancomicina, é a resistência heterogênea (heterorresistência) do S. aureus a esses antibióticos. Certas cepas apresentam a CMI baixa para vancomicina $(<4 \mu \mathrm{g} / \mathrm{ml})$ e meticilina $(<2 \mu \mathrm{g} / \mathrm{ml})$, mesmo sendo consideradas sensíveis por métodos convencionais de avaliação de sensibilidade. Cepas como essas podem conter subpopulações de células que apresentam $\mathrm{CMI} \leq 8$ $\mu \mathrm{g} / \mathrm{ml}$, numa freqüência de 1:106 células, que não podem ser detectadas pelos métodos convencionais ${ }^{(30,37)}$. A única forma de se detectar uma cepa heteroVISA (Staphylococcus 
aureus com resistência intermediária à vancomicina) é por meio da análise de suas subpopulações, em que são inoculadas diferentes diluições de uma suspensão bacteriana em meio de cultura sólido (adicionado de concentrações crescentes de vancomicina).

Embora o mecanismo de resistência do S. aureus contra a vancomicina não esteja bem esclarecido, acredita-se que esteja relacionado com o envolvimento do gene Van, que determina a resistência a essa droga em Enterococcus, que, provavelmente, é capaz de transmitir essa resistência, por meio de plasmídeos, para o $S$. aureus, uma vez que esse fenômeno foi observado em laboratório ${ }^{(41)}$. Porém, em um estudo recente, foram pesquisados os genes Van A e Van B, pela técnica da PCR, cujos resultados foram negativos. Surgiu, então, a nova hipótese de que o espessamento da parede celular seria responsável pela resistência à vancomicina. Estudos bioquímicos e de microscopia eletrônica de transmissão da parede celular de uma cepa VRSA sugerem que essa célula produz maiores quantidades de peptideoglicano e de monômeros de mureína (Figura 1). Nessas circunstâncias, uma maior quantidade de moléculas de vancomicina fica retida nas camadas de peptideoglicano, enquanto uma quantidade muito menor do antibiótico chega à membrana citoplasmática, onde ocorre a síntese do peptideoglicano $(9,36,41)$.

Desde o aparecimento das cepas MRSA, a vancomicina tem sido usada como droga de escolha para o tratamento empírico de infecções estafilocócicas. Lamentavelmente, já existem cepas resistentes a esse glicopeptídio, as conhecidas cepas $S$. aureus resistente à vancomicina (VRSA) ${ }^{(10,14)}$. De fato, o aumento do uso da vancomicina provocou uma pressão seletiva, o que levou ao surgimento de $S$. aureus e Staphylococcus coagulase-negativo com sensibilidade reduzida à vancomicina e a outros glicopeptídios ${ }^{(41)}$.

A resistência do $S$. aureus à vancomicina provoca alterações no aspecto macromorfológico das colônias, que se apresentam com aparência bastante heterogênea, dando a impressão de contaminação (Figura 1). Além disso, geralmente as cepas de $S$. aureus precisam de mais de 4 horas para positivar o teste da coagulase, levando a identificações errôneas de Staphylococcus coagulase-negativa ${ }^{(20,24)}$.

Nos últimos anos, surgiu a $S$. aureus associada à comunidade (CA-MRSA), que é uma cepa resistente à associação meticilina/oxacilina, como o próprio nome indica, somente encontrada nas comunidades; ou seja, essa cepa, diferentemente das cepas MRSA (mais conhecidas), não é encontrada em ambiente nosocomial. Os pacientes acometidos pelo CA-MRSA não foram internados em hospitais no ano anterior à infecção, nem foram submetidos a procedimen- tos médicos como diálise, cirurgia ou cateter, fatos muito comuns em infecção por $\operatorname{MRSA}^{(5,21,30)}$.

Das principais diferenças entre as cepas CA-MRSA e as associadas ao ambiente hospitalar (HA-MRSA), podemos destacar manifestações clínicas, em sua maioria associadas a infecções de pele e partes moles, além de muitos casos de infecções respiratórias e da corrente sangüínea. Outra característica extremamente importante é o perfil de resistência a antibióticos, pois, enquanto o HA-MRSA se caracteriza por uma ampla resistência a diversos antibióticos, as cepas CA-MRSA mostram uma sensibilidade (entre $85 \%$ e 100\%) a drogas, como clindamicina, gentamicina, ciprofloxacina, sulfametaxazol/trimetoprim e vancomicina, mostrando-se resistente apenas à oxacilina e a outros betalactâmicos ${ }^{(21,30)}$.

O perfil de resistência diferenciado entre as cepas HAMRSA e CA-MRSA parece ser explicado pela distribuição e pelo tamanho dos cassetes cromossomiais que contêm o determinante de resistência à meticilina $(\mathrm{SCCmec})^{(21,30)}$. Entre os cinco tipos de SCCmec (I, II, III, IV e V), somente os tipos I, II e III são encontrados em cepas HA-MRSA, enquanto que os tipos IV e V podem ser observados em cepas CA-MRSA, nas quais o tipo IV é menor e, provavelmente, facilita a perda dos genes de resistência a diversos antibióticos, conservando-a para betalactâmicos. Outra característica importante do CA-MRSA é a presença dos genes lukF-PV e lukS-PV, que codificam a leucocidina de Panton-Valentine (PVL), uma toxina capaz de induzir a destruição de leucócitos humanos e causar grande dano tecidual, sendo considerada um fator de virulência associado a infecções de pele primárias severas e pneumonias necrotizantes ${ }^{(21,22,30)}$.

$\mathrm{Na}$ literatura encontramos uma variedade de termos usados para descrever a resistência à vancomicina. O Clinical and Laboratory Standards Institute (CLSI, antes NCCLS) e a Sociedade Francesa de Microbiologia (SFM) utilizam as três seguintes classificações para a sensibilidade das cepas de $S$. aureus à vancomicina: sensivel $(\mathrm{CMl}<4 \mu \mathrm{g} / \mathrm{ml})$, intermediário $(8 \leq \mathrm{CMl} \leq 16 \mu \mathrm{g} / \mathrm{ml})$ e resistente $(\mathrm{CMl}>32 \mu \mathrm{g} / \mathrm{ml})$; entretanto, a Sociedade Britânica para a Quimioterapia Antimicrobiana (BSAC) e o Grupo Suíço de Referência para Antibióticos (SRGA) referem-se apenas a duas categorias: sensível $(\mathrm{CMl}>4 \mu \mathrm{g} / \mathrm{ml})$ e resistente $(\mathrm{CMl}>8 \mu \mathrm{g} / \mathrm{ml})$. Essas variações têm originado uma variedade de siglas, entre as quais as utilizadas para as cepas resistentes à vancomicina: VISA e VRSA. Devido ao fato de as cepas VISA e VRSA geralmente se mostrarem resistentes também à teicoplanina, foi proposto o uso de outras siglas: GISA (Staphylococcus aureus de sensibilidade intermediária aos glicopeptídios) e GRSA (Staphylococcus aureus resistente aos glicopeptídios). Várias 
cepas GISA foram isoladas a partir de 2000, em São Paulo, onde diversos fatores de risco podem contribuir para o seu surgimento, como o uso prolongado de vancomicina, por exemplo. Existem dificuldades descritas na identificação das cepas GISA, posto que os testes apresentando CMI elevada para glicopeptídios devem ser confirmados, já que a resistência à vancomicina é instável e o microorganismo pode deixar de expressar resistência. Outra denominação se refere às cepas que apresentam $\mathrm{CMl}<4 \mu \mathrm{g} / \mathrm{ml}$ (sensíveis) e subpopulações com CMl entre 8 e $16 \mu \mathrm{g} / \mathrm{ml}$, denominadas heteroVISA (h-VISA). Além disso, podemos encontrar denominações como CA-MRSA para identificar as cepas MRSA de origem comunitária e HA-MRSA, para cepas MRSA encontradas em

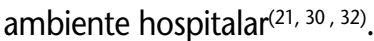

O combate às infecções provocadas pelas cepas de $S$. aureus resistentes aos glicopeptídios teicoplanina e vancomicina tem como alternativas terapêuticas as estreptograminas (quinupristina/dalfopristina), as oxazolidinonas, a glicilciclina (Tigeciclina ${ }^{\circledR}$ ), além da associação de vancomicina com um antibiótico betalactâmico antiestafilocócico ${ }^{(38)}$. As estratégias para o controle dessas cepas, por outro lado, incorporam as medidas profiláticas convencionais de combate às infecções em geral (lavagem das mãos, uso de luvas e manipulação adequada de dejetos e secreções); vigilância epidemiológica; isolamento; uso racional dos glicopeptídios e tratamento dos pacientes infectados ${ }^{(10,45)}$.

O combate às cepas de bactérias resistentes aos antibióticos e quimioterápicos é consideravelmente difícil, por isso devem-se adotar medidas que levem à redução do risco de desenvolvimento dessas cepas, aliando um tratamento criterioso com a orientação no sentido de que os pacientes cumpram a posologia da droga e o tempo do tratamento estabelecido na sua totalidade ${ }^{(4)}$. Paralelamente a isso, medidas complementares devem ser assumidas pelas autoridades responsáveis pelo controle da saúde pública, no desenvolvimento de condições sanitárias apropriadas e nos investimentos em pesquisas científicas que visem a descoberta de novos e mais eficientes antibióticos, quimioterápicos e vacinas para combater as bactérias multirresistentes, em particular, e os agentes infecciosos como um todo(4).

\section{Considerações finais}

A penicilina $G$ (descoberta por Alexander Fleming, em 1928) passou a ser usada no tratamento de pacientes infectados pelo S. aureus em 1943. Porém, logo esse patógeno exibia resistência àquele betalactâmico nos hospitais do Reino Unido e dos EUA. O mesmo ocorreu com a meticilina, (primeira penicilina semi-sintética lançada em clínica em 1960), com o aparecimento das cepas MRSA e com a vancomicina (conhecida desde 1956), contra a qual já existem cepas de S. aureus resistentes (VRSA). Hoje, felizmente, ainda existem alternativas terapêuticas contra as cepas resistentes aos glicopeptídios teicoplanina e vancomicina, como as estreptograminas (quinupristina/daltopristina), as oxazolidinonas e as associações de antibióticos, como vancomicina e betalactâmicos.

O desenvolvimento de mecanismos de resistência aos antibióticos demonstrado pelo $S$. aureus está diretamente relacionado com os procedimentos empregados na sua antibioticoterapia. Por outro lado, o entendimento do funcionamento da patogenicidade desse perigoso agente infeccioso pode orientar os profissionais de clínica na racionalização de sua antibioticoterapia, minimizando, assim, as chances de seleção de cepas resistentes (e multirresistentes) aos antimicrobianos. Sabendo-se que os índices de cepas MRSA em hospitais brasileiros variam de $40 \%$ a $80 \%$, principalmente em UTIs, a importância de se conhecer uma cepa de valor epidemiológico para o ambiente hospitalar já foi reconhecida. Fatores diversos reforçam essa importância, como a mortalidade e o custo atribuído à infecção por essas cepas, inferindo a necessidade de implementação de um programa de vigilância microbiológica ativa ${ }^{(46)}$. Existe, portanto, uma aplicabilidade prática do reconhecimento de cepas resistentes em que a melhoria, a diminuição do custo do tratamento e a contenção dessas cepas antes da infecção dos pacientes graves são os principais parâmetros a serem atingidos. Assim, compete também aos profissionais de saúde instruírem os seus pacientes para que cumpram a posologia dos antibióticos receitados. O descaso com a dosagem e com o tempo de duração do tratamento, bem como sua interrupção, tem sido uma das maiores barreiras à cura das infecções causadas pelo $S$. aureus ou por qualquer outro agente infeccioso. É imprescindível também que a saúde pública e a pesquisa científica do país façam investimentos em campanhas e inovações tecnológicas visando à educação da população e à descoberta (ou síntese) de novos e mais eficazes antibióticos e vacinas para combater, mais eficientemente, esses agentes infecciosos, principalmente os multirresistentes aos antimicrobianos.

\section{Agradecimentos}

Agradecemos o suporte financeiro do Conselho Nacional de Desenvolvimento Científico e Tecnológico (CNPq), da Fundação Carlos Chagas de Amparo à Pesquisa do Estado do Rio de Janeiro (FAPERJ) e da Universidade Federal Fluminense (UFF). 


\section{Referências}

1. ANDRIOLO, A. Guias de medicina ambulatorial e hospitalar. São Paulo: Editora Manole, 2005.

2. BERNARD, L. et al. Comparative analysis and validation of different assays for glycopeptide susceptibility among methicillin-resistant S. aureus strains. J Microbiol Meth, v. 57, p. 231-9, 2004.

3. BRAUNWALD, E. et al. Harrison Medicina Interna. 15. ed. Rio de Janeiro: Mcgraw-Hill Interamericana do Brasil, 2002.

4. BADDOUR, M. M.; ABUELKHEIR, M. A.; FATANI, A. $J$. Trends in antibiotic susceptibility patterns and epidemiology of MRSA isolates from several hospitals in Riyadh, Saudi Arabia. Ann Clin Microbiol Antimicrob, v. 5, n. 30, 2006

5. BRATU, S. et al. A population-based study examining the emergence of community-associated methicillinresistant S. aureus USA300 in New York City. Ann Clin Microbiol Antimicrob, v. 5, n. 29, 2006.

6. BALABAN, N. et al. Auto inducer of virulence as a target for vaccine and therapy against $S$. aureus. Science, v. 280, p. 438-40, 1998.

7. BANNERMAN, T. L. Staphylococcus, Micrococcus and other catalase-positive cocci that aerobically. In: MURRAY, P. R. et al. (eds.). Man Clin Microbiol. 8. ed. Washington, DC: ASM Press, 2003. vol. 1, p. 384-404.

8. CARVALHO, C. et al. Monitoramento microbiológico seqüencial da secreção traqueal em pacientes intubados internados em unidade de terapia intensiva pediátrica. J Pediatr, v. 81, n. 1, p. 29-33, 2005.

9. CASSETTARI, V. C.; STRABELLI, T.; MEDEIROS, E. A. S. Staphylococcus aureus bacteremia: what is the impact of oxacillin resistance on mortality? Braz J Infect Dis, v. 9, n. I, p. 70-6, 2005.

10. CDC. Interim guidelines for prevention and control of stafilococcal infection associated with reduced susceptibility to vancomycin. MMWR, v. 46, n. 26, p. 626-7, 1997.

11. CAVALCANTI, S. et al. Prevalence of Staphylococcus aureus introduced into intensive care units of a university hospital. Braz J Infect Dis, v. 9, n. 1, p. 5663, 2005.

12. CENTERS FOR DISEASE CONTROL AND PREVENTION. BRIEF REPORT. Vancomycin-resistant S. aureus - New York, 2004. MMWR Morb Mortal Wkly Rep, v. 53, p. 322-3, 2004.

13. DAVIS, J. S. Management of bone and joint infections due to Staphylococcus aureus. Int Med J, v. 35, p. 79S-96S, 2005.

14. FREITAS C. C.; FONSECA, A. Aspectos genéticosbioquímicos da resistência bacteriana aos antibióticos. In: ZANON, U.; NEVES, J. Infecções hospitalares: prevenção, diagnóstico e tratamento. Rio de Janeiro: MEDSI, 1987. p. 207-49.

15. FOSTER, T. J.; HOOK, M. Surface protein adhesins of Staphylococcus aureus. Trends Microbiol, v. 6, p. 484-8, 1998

16. GOSBELL, I. B. Diagnosis and management of catheterrelated bloodstream infections due to Staphylococcus aureus. Intern Med J, v. 35, p. 45S-62S, 2005

17. IWATSUKI, K. et al. Staphylococcal cutaneous infections: invasion, evasion and aggression. J Dermatol Sci, v. 42, p. 203-14, 2006

18. KONEMAN, E. et al. Diagnóstico microbiológico. 5 ed. Rio de Janeiro: Guanabara Koogan, 2001. cap. 11, parte 1.

19. LIMA, D. C. et al. Snake venom: any clue for antibiotics and cam? Evid Based Complement Alternat Med, v. 2, n. 1, p. 39-47, 2005.

20. LUTZ, L. et al. Clinical failure of vancomycin treatment of Staphylococcus aureus infection in a tertiary care hospital in southern Brazil. Braz J Infect Dis,v. 7, n. 3 p. 224-8, 2003.

21. LOPES, H. V. CA-MRSA: um novo problema para o infectologista. Rev Panam Infectol, v. 7, n. 3, p. 34-6, 2005.

22. LARCOMBE, L. et al. Rapid emergence of methicillinresistant Staphylococcus aureus (MRSA) among children and adolescents in northern Manitoba, 20032006. Can Commun Dis Rep, v. 33, n. 2, p. 9-14 2007.

23. LOWY, F. D. Medical progress: Staphylococcus aureus infections. N Eng J Med, v. 339, p. 520-32, 1998.

24. MAMISUKA, E. Projeto de resistência microbiana em serviços de saúde, Staphylococcus. ANVISA, 2005. Disponível em: <http//:www. anvisa. gov. br>.

25. MACHADO, A. et al. Cost-effectiveness of linezolid versus vancomycin in mechanical ventilation-associated nosocomial pneumonia caused by methicillin-resistant Staphylococcus aureus. Braz J Infect Dis, v. 9, n. 3, p. 191-200, 2005.

26. MICHELIM, L. et al. Fatores de patogenicidade e resistência a antimicrobianos em Staphylococcus epidermidis associados a infecções nosocomiais em unidades de terapia intensiva. Braz J Microbiol, v. 36 n. 1, p. 17-23, 2005.

27. MURCKO, M. A. Recent advances in ligand design methods. Rev Comp Chem, v. 11, p. 1-66, 1997.

28. NOVICK, R. P. Pathogenicity factors and their regulation. In: FISCHETTI, V. A. et al. (eds.). Washington DC: ASM Press, 2000. p. 392-407.

29. OLIVEIRA, G. A. et al. Avaliação da tolerância à vancomicina em 365 cepas hospitalares de Staphylococcus aureus resistentes à oxacilina. J Bras Patol, v. 37, n. 4, p. 239-46, 2001

30. RIBEIRO, J. et al. Prevalence of methicillin-resistant Staphylococcus aureus (MRSA) among patients visiting the emergency room at a tertiary hospital in Brazil. Braz J Infect Dis, v. 9, n. 1, p. 52-5, 2005.

31. ROBERT, S.; CHAMBERS, S. Diagnosis and management of Staphylococcus aureus infections of the skin and soft tissue. Intern Med J, v. 35, p. 97S-105S, 2005.

32. RODRIGUES, C. A.; VESGA, O. Staphylococcus aureus resistente à vancomicina. Biomédica, v. 25, p. 57587, 2005

33. REAGAN, D. R. et al. Elimination of coincident $S$. aureus nasal and hand carriage with intranasal application of 
mupiricin calcium ointment. Ann Intern Med, v. 114, p. 101-6, 1991.

34. SCHECHTER, M.; MARANGONI, D. V. Doenças infecciosas: conduta, diagnóstico e terapêutica. 2. ed. Rio de Janeiro: Guanabara Koogan, 1998.

35. SRINIVASAN, A.; DICK, J. D.; PERL, T. M. Vancomycine resistence in staphylococci. Clin Microbiol Rev, v. 15, n. 3, p. 430-8, 2002.

36. TAVARES, W. Manual de antibióticos e quimioterápicos antiinfecciosos. Rio de Janeiro: Editora Atheneu, 1999.

37. TAVARES, W. Bactérias Gram-positivas problemas: resistência do estafilococo, do enterococo e do pneumococo aos antimicrobianos. Rev Soc Bras Med Trop, v. 33, p. 281-301, 2000.

38. TAVARES, W. Manual de antibióticos e quimioterápicos antiinfecciosos. Rio de Janeiro: Editora Atheneu, 2002. caps. 1 e 5.

39. TENOVER, F. C.; MCDONALD, L. C. Vancomycin-resistent staphylococci and enterococci: epidemiology and control. Curr Op Infect Dis, n. 18, p. 300-5, 2005.

40. TRABULSI, L. R.; ALTHERTHUM, F. Microbiologia. Staphylococcus aureus. São Paulo: Atheneu, 2005. cap. 20, p. 175-82.

41. TIWARI, H. K.; SEN, M. R. Emergence of vancomycin resistant Staphylococcus aureus (VRSA) from a tertiary care hospital from northern part of India. BMC Infect Dis, v. 6, n. 156, 2006.

42. VELÁQUEZ, J. et al. Vigilancia de la resistencia de Staphylococcus aureus a la oxacilina-vancomicina y patrones de corresistencia. Rev Per Soc Med Intern, v. 15, n. 4, 2002.

43. VELÁZQUEZ-MEZA, M. E. Staphylococcus aureus methicillin-resistant: emergence and dissemination. Salud Pública de México, v. 47, p. 381-7, 2005.

44. WALSH, T. R.; ROBIN, A. H. The prevalenceand mechanisms of vancomycin resistence in Staphylococcus aureus. Ann Rev Microbiol, v. 56, p. 657-75, 2005.

45. WENZEL, R. P.; EDMOND, M. B. Vancomycin-resistant Staphylococcus aureus: infection control considerations. Clin Infect Dis, v. 27, n. 2, p. 245-51, 1998.

46. MUTO, C. A. et al. SHEA guideline for preventing nosocomial transmission of multidrug-resistant strains of Staphylococcus aureus and Enterococcus. Infect Control Hosp Epidemiol, v. 24, p. 362-86, 2003. 